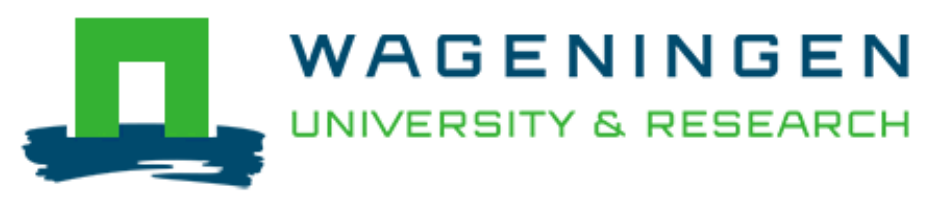

\author{
Responsible innovation and the reshaping of existing technological \\ trajectories: the hard case of genetically modified crops \\ Macnaghten, P.
}

This is a "Post-Print" accepted manuscript, which has been Published in "Journal of Responsible Innovation"

This version is distributed under a non-commercial no derivatives Creative Commons (c) (1) @ $\Theta$ (CC-BY-NC-ND) user license, which permits use, distribution, and reproduction in any medium, provided the original work is properly cited and not used for commercial purposes. Further, the restriction applies that if you remix, transform, or build upon the material, you may not distribute the modified material.

Please cite this publication as follows:

Macnaghten, P. (2016). Responsible innovation and the reshaping of existing technological trajectories: the hard case of genetically modified crops. Journal of Responsible Innovation, 3(3), 282-289.

https://doi.org/10.1080/23299460.2016.1255700

You can download the published version at:

https://doi.org/10.1080/23299460.2016.1255700 


\title{
Responsible Innovation and the Reshaping of Existing Technological Trajectories: The Hard Case of GM Crops
}

\author{
Phil Macnaghten \\ Macnaghten, P. (2016) Responsible innovation and the reshaping of existing technological \\ trajectories: the hard case of genetically modified crops. Journal of Responsible Innovation, \\ 3(3), 282-289. https://doi.org/10.1080/23299460.2016.1255700
}

\section{Introduction}

Whereas concepts and frameworks of responsible innovation have been developed and deployed in relation to novel and potentially transformative technologies - ranging from advanced biofuels (Capurro et al. 2015); climate geoengineering (Stilgoe 2015; Stilgoe et al. 2013), financial innovation (Asante et al. 2014), information and communication technology (Stahl et al. 2013; von Schomberg 2011), nanotechnology (Owen and Goldberg 2010), synthetic biology (Brian 2015; Technology Strategy Board 2012; UK Synthetic Biology Roadmap Coordination Group 2012) - inquiry has yet to address whether such frameworks offer potentials to open up governance arrangements on technologies that are already relatively mature, that already hold a certain degree of path dependency, and that may have already proved to be socially and politically controversial. If frameworks of responsible innovation are to prove successful in aligning innovation dynamics with societal values, they will have to demonstrate their capacities to shape existing technological trajectories, alongside those that remain 'in-the-making'.

Taking as a reference point Collingridge's control dilemma (Collingridge 1980), where dynamics of control lead technologies as they develop to become increasingly less amenable to societal shaping in the face of dynamics of power, lock-in and incumbent interests, agricultural (bio)technologies represent a 'hard case'. Those involving the genetic modification of plants, in particular, have been deeply mired in controversy, polemic and in some cases opposition. Unless we better understand why the governance of GM crops continues to evade policy resolution, attempts aimed at the genetic improvement of crops risk generating further controversy, misunderstanding and polemic. For this reason, GM crops represent a valuable case to examine whether frameworks of responsible innovation have traction in opening up new and more responsive governance options (the argument developed in this paper complements that of Kelly Branson who traces genetically engineered seed systems as cultural enterprises, and who argues the need to attend to the responsibility of innovations in their design; see Bronson 2015).

This perspective informed a major research project GM Futuros that was set up to ask two overarching questions: (a) to understand the dynamics of and responses to GM crops as embedded in local practices of key actors, namely farmers, scientists and publics; and (b) to explore the potential of frameworks of responsible innovation to reconfigure the debate on the governance of GM foods and crops, and to provide new pathways to move it away from its current polemic and impasse. The setting for the research was on three global 'rising power' countries. This was intentional. While the majority of scholarship on GM crops has focused on the Global North, it will be in countries in the Global South more where agricultural innovation is most needed, where the bulk of food provision is expected to come from and where debates over GM technologies are likely to be most intense. For this reason we choose to conduct detailed ethnographic qualitative work on farmers, scientists 
and publics, undertaken in collaboration with local partners-in Brazil on GM soya, in India on GM cotton and in Mexico on GM maize-engaging with the dynamics through which GM crops have been promoted, implemented and at times resisted across different scales and contexts by an inclusive array of actors.

Across the three case studies, we found that current approaches to the regulation and governance of GM crops have been dominated by risk-based assessment methodologies, the assumption being that the key criterion mediating their release should be an independent case-by-case risk assessment of their impacts on human health and the environment. One consequence of this framing is that the public debate surrounding GM crops has all too often been boiled down to one of safety: are they safe to eat, and are they safe to the environment? In relation to these questions we remain agnostic notwithstanding our view that the institutional structuring of the debate on the safety of GM crops may be exacerbating the polemic (Mampuys and Brom 2015). Our argument is that we need, in addition, to ask different questions. If we are to govern GM crops in a socially and scientifically robust fashion, we need to engage with the issue within the terms of the debate as it is considered by an inclusive array of actors.

In our empirical research Suzanna Carro-Ripalda and her team found that maize in Mexico was highly culturally resonant, deeply engrained in Mexican identity and history as well as in everyday food practices (Carro-Ripalda and Astier 2014; Carro-Ripalda et al. 2015). In ethnographic research with rural actors from the Pátzcuaro Lake area of the state of Michoacán we found that smallholder farmers retain strong and enduring relations around maize agriculture and that the prospect of GM maize is seen as an intrusion on traditional practices. In such a context, protests against GM maize can be seen to signify the defence of Mexican culture in the face of an unwanted form of imposed neoliberal globalization. In a laboratory ethnography conducted at the National Laboratory of Genomics for Biodiversity in Guanajuato (Langebio) we found that laboratory scientists we interviewed were divided on the use of genetic modification technologies on the maize genome. And we found that in focus group research with Mexican lay urban publics, people expressed a general negative reaction to GM crops and foods, reflecting deep-seated patterns of mistrust in the Mexican government, and their apparent collusion with large corporations.

In Brazil, Julia Guivant and her team found that even though the coverage of GM crops had risen rapidly since 2005 (mostly GM soya and maize), the issue is far from settled, with little evidence of public acceptability or inclusive governance (Guivant and Macnaghten 2015). We identified why the debate bred so much polemic up until 2005 , and the factors that contributed to the widespread adoption and take-up of GM crops in Brazil since 2005. We then identified through ethnographic research with rural actors from the southern state of Santa Catarina the various ways in which GM crop technologies have been adopted into local agricultural practices, where we found evidence of a conflict between farmers and technical experts from the seed companies, each blaming each other for the growing problem of weed resistance to glyphosate. In a laboratory ethnography conducted at the soya research division (CNPSO) of the state-owned agricultural research organisation Embrapa, we found clear and unqualified optimism among the scientists we interviewed on the role of GM crop technologies, with little evidence of a structured and sustained debate with wider society. Finally, In focus group research with lay urban publics, we found that Brazilian publics adopt negative views to GM crops and foods (although trusting in the expert systems), principally because the technology is seen to benefit the producer (not the consumer) and because they had not been consulted or clearly informed.

In India, Yulia Egorava and her team found that GM cotton had become a provocative symbol of foreign control and imposition, where regulatory bodies have been routinely 
criticized for using inadequate procedures for the approval of GM crops (Egorava et al. 2015). We found that the debate on GM crops has been mired in controversy, culminating in the 2013 ten-year moratorium on GM crops, including field trials. In ethnographic fieldwork research with rural actors in the Kalahandi district of western Odisha, we found evidence of widespread adoption of GM cotton, but also of 'lock-in' to the technology with indigenous seeds no longer so available. In a laboratory ethnography conducted at the New Delhi branch of the International Centre for Genetics and Biotechnology (ICGEB), we found that scientists whose work we observed were opposed to the moratorium and constructed and perceived the position of anti-GM actors as 'ignorant' or aimed at 'publicity' seeking. And in focus group research with urban and rural publics we identified (again) largely negative views from Indian publics to GM crops and foods, with trust once more being a critical dimensions.

Overall, across each of the research sites we found that the factors responsible for the controversy over GM crops were social, cultural and institutional in nature, in each case transcending questions of technical risk (Macnaghten 2015a). Thus, not surprisingly, the technical regulatory bodies charged with approving the release of GMOs had not provided 'authoritative governance' (Hajer 2009): that is, they had not lead to decisions, developed through reasoned, open and transparent deliberation, that were seen as trustworthy and as worthy of acceptance by the broader community. We then offered a typology aimed at explaining why the controversy surrounding GM crops had taken different forms in different national settings. Factors that were seen to be relevant in structuring the controversy included the perceived authority of the regulatory agencies, the cultural resonance of the crops in question, the level of intensity of protest movements, the extent to which GM can become represented as the symbol of wider struggle and the degree of sustained effort by institutional actors to engage the public.

Responding to this 'institutional void' (Hajer 2003) - namely, the lack of agreed structures or rules as to how technology should be governed in its 'beyond risk' dimensions - we examined whether frameworks of responsible innovation have traction in opening up new and more responsive governance options. Using the 'anticipation-inclusion-reflexivityresponsiveness' (AIRR) responsible innovation framework developed independently for the UK research councils (see Owen 2014; Stilgoe et al. 2013), we examined what responsible and inclusive governance could mean in relation to the actors involved in the governance of agricultural biotechnologies: what new institutional capacities are required to anticipate better the wider driving forces as well as the impacts of agricultural technologies, how to open up an inclusive debate with stakeholders and wider publics, how to develop more reflexive scientific cultures and what kinds of new governance architectures are needed that are responsive to these processes (Macnaghten 2015b).

A further innovation in our research was our attempt to open up the debate on the governance of GM crops was through a set of commentaries from a number of pre-eminent scholars and practitioners across the crop science, policy studies, science and technology studies and anthropology communities. The commentators were all participants in a policy workshop organised at the Royal Society in June 2014, designed to draw lessons from the GM Futuros research, and to explore the future of GM policy in the UK and Europe within a responsible innovation framework.

In relation to the dimension of anticipation, given that at least first generation GM crops have been developed and adopted throughout much of the developed and developing world, an anticipative approach requires in addition a systematic contextualisation of GM crops' social and ethical impacts, as a precondition for imagining how they could be otherwise configured. That is to say, a better understanding of the context out of which GM crops 
developed is required, of the kinds of social worlds they have contributed towards, and thus, by implication, of how such contexts may need to be reconfigured if GM crops (and associated developments in the crop sciences) are to contribute to more inclusive, socially just and environmentally sustainable futures. Our commentators pointed to three aspects that may have been insufficiently overlooked in the literature: the relationship between GM crops and its origins in neoliberal policymaking (Levidow 2015), the associated extent to which GM crops are implicated in 'the gradual neoliberal collectivisation of agriculture by private corporations' (Northcott 2015); and the need for methodologies that are equipped to develop non-reductionist accounts of the relationship between GM crops and everyday practices that include emphasis on the problems GM crops may cause in people's livelihoods, alongside technical considerations of risk (Harvey 2015).

Responding to the dimension of inclusion, our commentators pointed to the insights arising from the deliberative research with publics and smallholder farmers as a necessary antidote to the narrative that presents the adoption of GM crops in Global South contexts as an unequivocal success story, 'a story of radical and progressive technological change that has been embraced by literally millions of farmers, the great majority of them smallholder producers in the "developing world"' (Glover 2015: 229). Glover highlights how the study counters this narrative: through the finding that both growers and consumers in each of the case settings felt ill-informed about the technology and excluded from decision-making processes, through the ethnographic field research that demonstrated that smallholder farmers evinced little trust in the technical advisors of the extension services, and through more widespread and at times pervasive breakdowns in public trust in the institutions of science, governance and regulation. Deliberative processes were seen to offer the potential of opening up governance discussions only when they are framed broadly, are open to the reframing relevant questions and to questions of political economy, and are aimed at helping policy-makers clarify issues, expand choice and reflect on the implications of alternative courses of action.

Responding to the dimension of reflexivity, and to the finding reported in the research that the scientists we interviewed had proved strikingly rigid in their capacity to reflect on the norms and value-laden assumptions underpinning their social imaginary of agricultural development which remained resolutely top-down, expert driven and technocratic, our commentators reflected on the question as to what kind of scientific culture we need for responsible agricultural innovation. While our molecular science commentators stressed the need to embed agricultural innovation in the context of global food security, of a future population predicted to grow to over 9 billion by 2015, and to do so securely, sustainably and equitably (Crute 2015; Lindsey 2015); a number of our other commentators stressed the need for more critical reflection on the 'mutual incomprehension' that is often evident between crop scientists and an informed lay food-eating public (Northcott 2015). To assist in such reflexivity, commentators pointed to the need for greater sensitivity to the relationality that exist between people and land, to the mechanistic and reductionist frame that commonly exists in crop science laboratory practices and to the impacts posed by the neoliberal collectivistation of global agriculture on questions of human freedom, dignity and sovereignity.

Responding to the dimension of responsiveness, and to the finding of remarkably unresponsive science policy institutions across each of the case sites, our commentators pointed to the structural conditions that often accompany institutional rigidities (Raina 2015), to the obvious interest of certain actors (e.g. seed companies) not to open up the debate on governance beyond their risk dimensions, and to the difficulty of reconciling conflicting interests and visions that may be intrinsically difficult to reconcile. 
Notwithstanding these structural constraints, our commentators pointed to the value of public research on these matters as a strategic priority, to how new policy architectures could be crafted, and to the virtue of a coherent alternative model of governance should opportunities in the wider polity emerge.

To conclude, as Sheila Jasanoff states in her endorsement of the book, Governing Agricultural Sustainability: Global Lessons from GM Crops can be seen as an attempt to apply frameworks and approaches to responsible innovation to 'prod the GM debate out of its current stalemate'. Moving beyond the domains of scientific risk assessment, the volume and its associated research opens up discussion of technological innovation to questions of globalization, political and economic power, and cultural identity. The still-prevalent information deficit model, alongside those that emphasise formal risk assessment, are seen as highly impoverished means to resolve controversy, and, in its place, responsible innovation is presented as an alternative pluralistic and inclusive model for decision-making that just might move us towards better governance of technological change in the food and agriculture domain. 


\section{Bibliography}

Asante, K., Owen, R. and Williamson, G. 2014. "Governance of new product development and perceptions of responsible innovation in the financial sector: insights from an ethnographic case study." Journal of Responsible Innovation 1 (1): 9-30.

Brian, J. 2015. "Special perspectives section: responsible research and innovation for synthetic biology." Journal of Responsible Innovation 2 (1): 78-80.

Bronson, K. 2015. "Responsible to whom? Seed innovations and the corporatization of agriculture." Journal of Responsible Innovation 2 (1): 62-77.

Capurro, G., Longstaff, H., Hanney, P. and Secko, D. 2015. "Responsible innovation: an approach for extracting public values concerning advanced biofuels." Journal of Responsible Innovation 2 (3): 246-265.

Carro-Ripalda and Astier, M. 2014. "Silenced voices, vital arguments: smallholder farmers in the Mexican GM maize controversy." Agriculture and Human Values 31 (4): 655-663.

Carro-Ripalda, S., Astier, M. and Artia, P. 2015. "An analysis of the GM crop debate in Mexico." In Macnaghten, P. and Carro-Ripalda, S. (eds.) Governing Agricultural Sustainability: Global Lessons from GM Crops. London: Routledge pp 33-73.

Colingridge, D. 1980. The Social Control of Technology. London: Frances Printer

Crute, I. 2015. "The route to food security is not through the glorification of the rural idyll and demonization of global trade (or visa versa)." In Macnaghten, P. and CarroRipalda, S. (eds.) Governing Agricultural Sustainability: Global Lessons from GM Crops. London: Routledge pp 155-160.

Egorova, Y., Raina, R. and Mantuong, K. 2015. "An analysis of the GM crop debate in India." In Macnaghten, P. and Carro-Ripalda, S. (eds.) Governing Agricultural Sustainability: Global Lessons from GM Crops. London: Routledge pp 105-135.

Glover, D. 2015. "Public participation, accountability and the stewardship of transgenic crops." In Macnaghten, P. and Carro-Ripalda, S. (eds.) Governing Agricultural Sustainability: Global Lessons from GM Crops. London: Routledge pp 167-173.

Hajer, M. 2003. "Policy without polity? Policy analysis and the institutional void." Policy Sciences 36: 175-195.

Hajer, M. 2009. Authoritative Governance. Oxford: Oxford University Press.

Harvey, P. 2015. "An anthropological perspective on the promise and threat of GM crops." In Macnaghten, P. and Carro-Ripalda, S. (eds.), Governing Agricultural Sustainability: Global Lessons from GM Crops. London: Routledge, pp. 174-178.

Levidow, L. 2015. "Neoliberal origins of anti-GM protest in Europe." In Macnaghten, P. and Carro-Ripalda, S. (eds.), Governing Agricultural Sustainability: Global Lessons from GM Crops, London: Routledge, pp. 179-185.

Lindsey, K. 2015. "GM Futures: perspectives from a plant molecular biologist." In Macnaghten, P. and Carro-Ripalda, S. (eds.) Governing Agricultural Sustainability: Global Lessons from GM Crops. London: Routledge pp 155-160.

Macnaghten, P. 2015a. "Comparing GM crops in Mexico, Brazil and India." In Macnaghten, P. and Carro-Ripalda, S. (eds.), Governing Agricultural Sustainability: Global Lessons from GM Crops, London: Routledge, pp.136-150.

Macnaghten, P. 2015b. "A responsible innovation framework for GM crops." In Macnaghten, P. and Carro-Ripalda, S. (eds.), Governing Agricultural Sustainability: Global Lessons from GM Crops, London: Routledge, pp.225-239.

Macnaghten, P. and Carro-Ripalda, S. (eds.) 2015. Governing Agricultural Sustainability: Global Lessons from GM Crops. London: Routledge.

Mampuys, R. and Brom, F. 2015. "Governance strategies for responding to alarming studies on the safety of GM crops." Journal of Responsible Innovation 2 (2): 201-219. 
Northcott, M. 2015. "Crop science, the Heisenberg Principle and Resistance to Genetically Modified Crops." In Macnaghten, P. and Carro-Ripalda, S. (eds.) Governing Agricultural Sustainability: Global Lessons from GM Crops. London: Routledge pp 198-204.

Owen, R. 2014. "The UK Engineering and Physical Sciences Research Council's commitment to a framework for responsible innovation." Journal of Responsible Innovation 1 (1): 113-117.

Owen, R. and Goldberg, N., 2010. Responsible innovation: a pilot study with the UK Engineering and Physical Sciences Research Council. Risk Analysis 30, 1699-1707.

Raina, R. 2015. "Institutional rigidities and impediments: agricultural research and GM crops in India." In Macnaghten, P. and Carro-Ripalda, S. (eds.) Governing Agricultural Sustainability: Global Lessons from GM Crops. London: Routledge pp 212-219.

Stahl, B., Eden, G. and Jirotka, M. (2013) "Responsible research and innovation in information and communication technology: Identifying and engaging with the ethical implications of ICTs." In R. Owen, J. Bessant and M. Heitz (eds.), Responsible Innovation: Managing the responsible emergence of science and innovation in society, Chichester: John Wiley, pp. 27-50.

Stilgoe, J. 2015. Experiment Earth: Responsible Innovation in Geoengineering. London: Routledge.

Stilgoe, J., Owen, R. and Macnaghten, P. 2013. Developing a framework of responsible innovation, Research Policy, 42: 1568-1580.

Technology Strategy Board [TSB] 2012. Responsible Innovation Framework for Commercialisation of Research Findings: For use in synthetic biology feasibility studies competition 2012, available at http://webarchive.nationalarchives.gov.uk/20130221185318/www.innovateuk.org/ a ssets/responsible innovation.pdf (accessed 25 February 2016).

UK Synthetic Biology Roadmap Coordination Group (2012) Synthetic Biology Roadmap, https://connect.innovateuk.org/documents/2826135/6376842/Synthetic+Biology+Ro admap+-+Report.pdf/ba60f764-1d05-42a6-9fae-b4dc97826a7d (accessed 25 February 2016).

von Schomberg, R. (ed.) (2011) Towards Responsible Research and Innovation in the Information and Communication Technologies and Security Technologies Fields. European Commission, http://ec.europa.eu/research/sciencesociety/document library/pdf 06/mep-rapport-2011 en.pdf (accessed 25 February 2016). 